\title{
Proteínas expresadas durante la periodontitis crónica. Revisión de la literatura
}

\section{Expression of proteins in chronic periodontitis. Literature review}

\author{
DÍAZ CABALLERO A* \\ ARÉVALO TOVAR $L * *$ \\ SIMANCAS PALLARES IM***
}

\begin{abstract}
Díaz Caballero A, Arévalo Tovar L, Simancas Pallares M. Proteínas expresadas durante la periodontitis crónica. Revisión de la literatura. Av Periodon Implantol. 201 1; 23, 2: 113-122.
\end{abstract}

\section{RESUMEN}

La periodontitis resulta en un daño tisular complejo en las estructuras de soporte dentario debido al efecto de la respuesta inmune. Sin embargo, la naturaleza de los componentes de esteproceso son interés de muchos investigadores y se determinaron a través de estudios experimentales algunas moléculas de carácter proteínico que activan y/o regulan otras sustancias y/o células para el desarrollo de la lesión. El objetivo de esta revisión de literatura es conducir un análisis crítico de la evidencia disponible sobre las proteínas expresadas durante la periodontitis crónica y su correlación con los cambios clínicos producidos en las lesiones. Se identificaron las publicaciones más relevantes a través de una búsqueda en bases de datos electrónicas como MEDLINE, EBSCO-HOST y "The Cochrane Database of Systematic Reviews". Para ser incluidos en la revisión, los estudios debieron definir la proteína investigada, en pacientes con periodontitis crónica. Los experimentos que investigaban proteínas expresadas en gingivitis y tumores fueron excluidos. De los 1210 artículos obtenidos en la fase inicial de la revisión, sólo 175 estaban disponibles en full text y de éstos sólo cumplieron los requisitos de inclusión 25 artículos, los cuales fueron confrontados, analizados y discutidos posteriormente. La evidencia disponible demuestra que las proteínas juegan un papel importante en la transducción de señales y que utilizan diversas vías para activar compuestos químicos y así contribuir al desarrollo de lesiones periodontales crónicas.

PALABRAS CLAVE: Periodontitis, inflamación, bacterias, proteínas.

\section{SUIMIMARY}

Periodontitis is a complex tissue damage to the supporting structures of teeth due to the effect of the immune response. However, the nature of the components of this process are of interest to many researchers and were determined through experimental studies of some molecules that activate a protein or regulating other substances and cells for the development of the lesion. The aim of this literature review is to conduct a critical analysis of available evidence on the expressed proteins in chronic periodontitis and its clinical correlation with the changes produced in the lesions. We identified relevant publications through a search of electronic databases such as MEDLINE, EBSCO HOST, and The Cochrane Database of Systematic Reviews. The search was conducted by two of the authors. To be included in the review, studies had to define the protein investigated in patients with chronic periodontitis. Experiments investigating protein expressed in gingivitis and tumors were excluded. Of the 1210 articles retrieved from the initial phase of the review, only 175 were available

* Odontólogo. Profesor titular Facultad de Odontología Universidad de Cartagena.

** Odontóloga. Profesora Titular Universidad de Cartagena. Decana Facultad de Odontología Universidad de Cartagena.

*** Odontólogo Consultor. Integrante Grupo Interdisciplinario de Tratamientos Odontológicos (GITOUC). Facultad de Odontología Universidad de Cartagena. 
in full text and they only met the requirements including 25 articles, which were confronted, analyzed and discussed later. Available evidence shows that proteins play an important role in signal transduction pathways that use various chemicals to activate and thereby contribute to the development of chronic periodontal lesions.

KEY WORDS: Periodontitis, inflammation, bacteria, proteins.

Fecha de recepción: 2 de julio de 2009.

Fecha de aceptación: 10 de julio de 2009.

\section{INTRODUCCIÓN}

La periodontitis es reconocida por una inflamación que se extiende en profundidad en los tejidos y causa pérdida de tejido se soporte conectivo y hueso alveolar. Resulta en la formación de bolsas periodontales o surcos profundizados patológicamente entre la encía y la raíz del diente (1). El mecanismo fisiopatológico por el cual ocurre esta sucesión de fenómenos tiene explicación en la respuesta inmune del hospedero frente a los microorganismos productores de toxinas (endotoxinas bacterianas) conocidos ampliamente como periodontopatógenos. Estas endotoxinas estimulan las células defensivas de los tejidos periodontales a que expresen varios mediadores inflamatorios entre los cuales están la interleuquina 1 (IL-1), el factor de necrosis tumoral alfa (FNT- $\alpha$ ) o receptor activador del factor $\kappa ß$ ligando (RANKL) (2). En adición a estos mediadores inflamatorios también se liberan otros productos endógenos como las proteínas de choque térmico 60 (HSP60), proteína $\mathrm{C}$ reactiva (CRP), lactoferrina, calprotectina, defensinas, lamininas, proteína quimioatrayente de monocitos, entre otras sustancias potencialmente citotóxicas.

En la fase aguda de respuesta a las bacterias patógenas, los "toll-like receptors" (TLR) activan vías de transducción en ambas respuesta inmune innata y adaptativa, así como también las HSP60 regulan a los macrófagos en el tejido local para producir citoquinas proinflamatorias. Una de éstas citoquinas es la interleuquina $1 ß$ (IL-1ß), asociada con la pérdida de inserción de tejido conectivo periodontal y reabsorción de hueso alveolar (3-5). Cuando la respuesta inflamatoria aguda es insuficiente, estas citoquinas estimulan los hepatocitos a la secreción de proteínas de fase aguda tales como la proteína $\mathrm{C}$ reactiva (CRP) durante el proceso de respuesta inflamatoria crónica sistémica no específica (6).

\section{MATERIALES Y MÉTODOS}

Se condujo una búsqueda electrónica de literatura a través de bases de datos como: MEDLINE (Ovid), Cochrane database of systematic reviews, Dentistry \& Oral Sciences Source (EBSCO-Host) desde 1960 hasta julio de 2009; con palabras clave como: proteins, periodontitis, lactoferrin, defensin, calprotectin, laminin. La búsqueda se limitó a documentos en inglés en donde se definiera claramente la metodología usada, que incluyera pacientes con periodontitis crónica.

Posterior a esto se procedió a realizar un tamizaje de los artículos encontrados en las bases de datos, con lo cual se seleccionaron 25 artículos que cumplieron con los criterios de inclusión, que fueron posteriormente analizados y discutidos.

\section{RESULTADOS Y DISCUSIÓN}

Existen varios compuestos de carácter proteínico expresados durante el desarrollo de la periodontitis, específicamente, interviene la proteína quimioatrayente de monocitos l (MCP-1), también conocida como citoquina pequeña inducible A2 (SCYA2) o CCL2. Esta proteína estimula ambos eventos; la quimiotaxis de monocitos y algunos procesos celulares asociados con la quimiotaxis, incluyendo el flujo de calcio y la expresión de integrinas (7-9). Es también, un inductor débil de la expresión de citoquinas en monocitos y, en concentraciones altas, provoca una interrupción respiratoria que conlleva a la generación de radicales libres. En adición, se demostró que la MCP-1 es sintetizada en la encía inflamada por las células del endotelio vascular y fagocitos mononucleares (10). La MCP-1 también puede ser sintetizada por otras células tales como leucocitos, queratinocitos y osteoblastos, en respuesta a estímulos endógenos o exógenos. 


\section{TABLA 1}

\section{EBSCO HOST - Dentistry \& \\ Oral sciences source}

1. Proteins

2. Chronic Periodontitis

3. Periodontal disease

4. Lactoferrin

5. Defensin

6. Calprotectin

7. Laminin

8. C reactive Protein

9. Heat shock protein

10. Monocite chemoattractant protein

1 AND 2

1 AND 3

2 AND 4

2 AND 5

2 AND 6

2 AND 7

2 AND 8

2 AND 9

2 AND 10

2 AND 3 AND 4 AND 5 AND 6 AND 7

AND 8 AND 9 AND 10

\section{OVID (MEDLINE - CDSR)}

1. Proteins

2. Chronic Periodontitis

3. Periodontal disease

4. Lactoferrin

5. Defensin

6. Calprotectin

7. Laminin

8. C reactive Protein

9. Heat shock protein

10. Monocite chemoattractant protein

\section{AND 2}

1 AND 3

2 AND 4

2 AND 5

2 AND 6

2 AND 7

2 AND 8

2 AND 9

2 AND 10

2 AND 4 AND 5 AND 6 AND 7 AND 8 AND 9 AND 10
Se demostró que la IL-1ß y el FNT- $\alpha$ inducen y estimulan mancomunadamente la expresión de MCP-1 en fibroblastos de ligamento periodontal humano, así estas citoquinas potentemente proinflamatorias contribuyen al infiltrado leucocitario (11).

Tonetti et al, en 1994, demostraron la presencia de ARNm para MCP-l en biopsias de tejidos tomadas de sitios con enfermedad periodontal. La MCP-l fue detectada en el epitelio oral especialmente en la capa basal así como en el infiltrado inflamatorio en el tejido periodontal enfermo (12).
132

3212

8757

4562

1261

104

982

1

9

2

3

11

5

3

180
Pradeep, Daisy y Hadge en 2009, en un estudio para determinar los niveles de MCP-l en el fluido crevicular gingival (FCG) por medio de ELISA, concluyen que los niveles de MCP-1 incrementan progresivamente con la progresión de la enfermedad y disminuyen después del tratamiento. Los niveles de MCP-l se correlacionan positivamente con los parámetros clínicos como el índice gingival, profundidad al sondaje y nivel de inserción clínica, así este puede ser considerado como un biomarcador en enfermedad periodontal y también merece consideraciones futuras como enfoque de tratamiento (13).

La proteína C reactiva (CRP: C - Reactive Protein), como se mencionó anteriormente es producida en el hígado ante influjo de otras citoquinas y también contribuye a la respuesta no específica en la mayoría de las formas de inflamación, infección y daño tisular (14). Algunos estudios experimentales demostraron que la CRP se une a sus ligandos expuestos en tejido enfermo y de esta manera activa el sistema de complemento, el cual puede inducir exacerbación (mediada por el complemento) de la injuria tisular.

1028

632

275

3349

13762

2993

2482

163

574

9

2

3

13

46

3

35

175
En una revisión sistemática de la literatura aplicando metaanálisis Paraskevas et al, en 2007, concluyen que existe amplia evidencia señalando que la periodontitis provoca una respuesta de fase aguda a moderada con elevación de los niveles de CRP comparados con los controles sanos; debido a que existen otros factores de base que a menudo se relacionan con la aparición de CRP como infecciones crónicas, enfermedades inflamatorias, tabaquismo, obesidad y trauma, quienes pueden actuar como factores de confusión. Sin embargo los estudios de tratamiento disponible son insuficientes. También sugieren que los estudios posteriores deben enfocarse a investigar los cambios en los marcadores moleculares y celulares en sangre periférica.

Recientemente se comprobaron los efectos de la actividad física en la disminución de la respuesta inflama- 
toria, demostrado en el estudio de Sanders et al en 2009 , que en un estudio de casos y controles anidado de 751 pacientes con periodontitis crónica moderada y severa obtienen como resultados que los individuos que emprenden actividad física cerca de 30 minutos diariamente o más, tienen niveles más bajos de biomarcadores proinflamatorios como CRP e IL-1ß en GCF que aquellos menos activos. Esta situación aplica a todos los individuos independientemente de su caso de periodontitis (15).

Linden et al, en 2008, en un estudio de asociación de niveles de CRP con enfermedad periodontal severa, tomaron 806 hombres con 6 o más dientes con niveles altos (> $3 \mathrm{mg} / \mathrm{l}$ ) o con niveles bajos de CRP en ambos puntos de inicio del tiempo de medición. Obtienen como resultado 67 hombres con un nivel $>3 \mathrm{mg} / \mathrm{l}$ y 739 hombres con un nivel $\leq 3 \mathrm{mg} / \mathrm{l}$ en ambos puntos de tiempo. Concluyen que existe una asociación entre los niveles de CRP y la periodontitis en el grupo de pacientes europeos entre los 60-70 años de edad (16).

Otra macromolécula expresada durante la enfermedad periodontal es la calprotectina; que es una proteína citosólica mayor derivada de los granulocitos, detectada en monocitos macrófagos (constituye cerca del 50-60\% del citosol) y células epiteliales (1718). Esta proteína de unión de calcio de $36,5 \mathrm{kDa}$ encaja en la familia de las proteínas $\mathrm{S} 100$ y está compleja y heterogéneamente compuesta de subunidades ligeras (MRP8, S100A8, calgranulin A) y pesadas (MRP14, S100A9, calgranulin B) las cuales son llamadas también "proteína relatada del factor inhibitorio de la migración de macrófagos 8 y 14" (MRP8/MRP14: macrophage migration inhibitory factor-released protein 8 and 14). Se conoce que los niveles de calprotectina incrementan en pacientes con algunas enfermedades incluyendo infecciones, tumores malignos y reacciones alérgicas. En particular, las concentraciones de calprotectina en plasma, orina y líquido sinovial de pacientes con enfermedades inflamatorias p. ej.: neumonía, meningitis, infección de vías urinarias, artritis reumatoide y fibrosis quística, se encontraron altos que aquellos líquidos de pacientes sanos (19).

Recientemente se demostró que la calproctetina está en niveles considerables no sólo en pacientes con cálculo dental; sino también en el fluido crevicular gingival (GCF-Gingival Crevicular Fluid) y que esa concentración fue significativamente más alta en pacientes con periodontitis (20-22). Schlegel et al (23), demostraron que la calprotectina es fuertemente expresada en el área de células inflamatorias en el tejido gingival de pacientes con periodontitis. En la enfermedad periodontal incrementan los neutrófilos, monocitos/macrófagos y linfocitos en el tejido de soporte inflamado y desempeñan un papel importante en la respuesta inmune del hospedero (24).

Esta proteína, también puede contribuir a la respuesta inmune en la enfermedad periodontal debido a que posee actividad antimicrobiana contra Candida albicans, Capnocitophaga sputigena, y Escherichia coli, actividad protectora contra Porphyromonas gingivalis en el epitelio gingival y una acción inhibitoria en el crecimiento de macrófagos y linfocitos (25-26). Su origen y los factores que regulan su liberación de las células inmunes siguen sin aclarar en la periodontitis. Miyasaki et al. Sugirieron que la mayor fuente de calprotectina en el fluido crevicular gingival eran los neutrófilos, basados en la correlación entre la los niveles de calprotectina y lactoferrina en el fluido crevicular gingival.

Actualmente se descubrió que la calprotectina existe en los tejidos gingivales con un infiltrado inflamatorio de células y lipopolisacáridos de $P$. gingivalis (P-LPS) induciendo a la liberación de calprotectina por parte de los neutrófilos (27). Es conocido que la P. gingivalis es el mayor patógeno de la periodontitis y que el PLPS afecta las funciones de los leucocitos estimulando la producción de citoquinas inflamatorias incluyendo IL-1 1, FNT- $\alpha$, e IL- 6 de los leucocitos y monocitos (28). En la transducción de señales de LPS, éste se une a la proteína de unión al LPS en el suero e interactúa con el CD14, el principal receptor entonces con los TLR, con un receptor de transmembrana el cual activa a la transcripción al factor nuclear $\kappa \beta(\mathrm{NF}-\kappa \beta)(29)$. Gracias a este mecanismo de CD14-TLR y NF- $\kappa \beta$, el PLPS induce la producción de IL- 1 y la expresión de RNAm de IL-6 e IL-8 en los neutrófilos y fibroblastos humanos; además el P-LPS puede regular la viabilidad, apoptosis y funciones fisiológicas de los neutrófilos (30-32).

Kido et al, en 1999 en un estudio de correlación entre los niveles de calprotectina en el fluido gingival crevicular e indicadores clínicos (profundidad al sondaje y sangrado al sondaje) y los niveles de IL-1ß $\mathrm{PGE}_{2}$ en el fluido gingival crevicular, recolectaron las muestras de individuos con enfermedad periodontal crónica y se realizaron pruebas de ELISA para determinar los niveles de IL- $1 B, P_{2} E_{2}$ y calprotectina. Obtienen como resultados que los niveles de calprotectina se relacionan significativamente en los sitios del sangrado a sondaje positivos, que en los sitios de sangrado al sonda- 
je negativos. Estos resultados indican que los niveles de calprotectina en el fluido gingival crevicular se correlacionan bien con los marcadores clínicos y bioquímicos en la enfermedad periodontal por lo cual puede ser usada para evaluar la extensión de la inflamación periodontal (33).

Kojima et al, en el 2000, en una investigación para la determinación de la presencia de péptidos de la calprotectina (S100A8 - S100A9) comparando sujetos sanos y/o con enfermedad periodontal a través de la realización de electroforesis en gel de poliacrilamida bidimensional (2-D SDS-PAGE), secuenciación aminoacídica $\mathrm{N}$-terminal, espectrometría de masa y western blot; obtienen como resultado que a través de la secuenciación se pudo identificar a los péptidos, además la presencia de MRP8 y MRP14 en el fluido crevicular gingival fue confirmado a través de western blot con anticuerpos monoclonales. Por tanto, se deduce que pueden jugar un papel importante en el surco gingival y que pueden representar posibles marcadores para la enfermedad periodontal.

Las lamininas son glicoproteínas de alto peso molecular $(900 \mathrm{kDa})$ y componentes mayores de la membrana basal, las cuales poseen múltiples roles estructurales y funcionales en la diferenciación, proliferación, adhesión y migración de células $(34,35)$; específicamente en las células del epitelio de unión en los procesos de formación de bolsas periodontales (36). Estas proteínas intactas son proteínas adhesivas ampliamente conocidas, derivadas de las células epiteliales, localizadas en el anclaje de los filamentos dentro del espacio de lámina lúcida del epitelio gingival y de unión (37). Son secretadas por las células epiteliales y se encuentran conformadas por tres cadenas de polipéptidos ( $\alpha 3, \beta 3$ y $\gamma 2)$, por tanto se sugirió que tiene forma de heterotrímero cruzado: de los cuales el último es específico para laminina-5 (38).

Puede estimular la migración celular, como se comentó anteriormente, después de unir las enzimas proteolíticas, mientras que esta misma proteína pero intacta, sirve como anclaje de las células epiteliales en la membrana basal. Ciertas metaloproteinasas de la matriz (MMPs) puede procesar la cadena $\gamma 2$ de la laminina-5, produciendo fragmentos de 40 y $70 \mathrm{kDa}$. Esta cadena unida a su enzima puede mediar reacciones inflamatorias para la regulación de la adhesión celular, migración y proliferación de fibroblastos, células epiteliales; los fragmentos sirven como quimioatrayentes leucocitarios. En resumen, estos fragmentos cumplen funciones activas, fisiológicas y/o patológicas en los procesos de remodelado tisular e inducción epitelial (39-41).

Pirilä et al, en 2001 (40), mostró que las cadenas $\gamma 2$ de la laminina-5 humana, estaba unida con las MMPs dentro del área de la membrana basal en la encía humana en los sitios de inflamación periodontal. Así mismo, Figueredo y Gustafsson, en 2000 (42), examinaron la presencia de lamininas en el fluido crevicular gingival (GCF) de pacientes con diferentes enfermedades periodontales y encontraron una elevación total de los niveles de laminina en el GCF de estos pacientes.

Las defensinas son un grupo pequeño de péptidos catiónicos ricos en cisteína con actividad antimicrobiana potente contra las bacterias gram negativas y gram positivas (43-44) (hBD-l: débil contra gram negativos, hBD2 es más activo contra gram negativos, y hBD3 es efectivo contra gram positivos), hongos y virus. Se encuentran de dos formas: las $\alpha$ defensinas (de origen intestinal y neutrofílico) y $ß$ defensinas (de origen epitelial). Existen por lo menos seis (6) formas de $\alpha$ defensinas identificadas; incluyen cuatro péptidos neutrofílicos, HNPl-4, y otros dos tipos conocidos defensinas humanas 5 y 6 (HD-5 y HD-6) (45-46). La HNP1-3 es expresada por los neutrófilos como parte de su mecanismo no oxidativo antimicrobiano. Son identificadas en las células de Paneth en el intestino así como también en la saliva (47). Diversos estudios usando anticuerpos y técnicas de hibridación in situ detectaron $\alpha$ defensinas en neutrófilos en el epitelio de unión indiferenciado.

Son péptidos antimicrobianos (AMPs: Antimicrobial Peptides) pequeños, catiónicos, expresados principalmente en las células epiteliales y todos los epitelios humanos (48), secretadas en fluidos biológicos, incluyendo, orina, fluidos bronquiales, secreciones nasales, saliva y fluido crevicular gingival (GCF) (49). En la cavidad oral, son expresadas en encía, lengua, glándulas salivales, mucosa y encontradas principalmente en condiciones inflamatorias y carcinomas (50). Las hBDs1 son expresadas en tejidos epiteliales, mientras que hBDs-2 y 3 son típicamente expresadas cuando los epitelios son estimulados por bacterias u otros mediadores inflamatorios (51).

En tejidos gingivales sanos, se encuentra expresión de ARNm de las hBD-1 y 2 en la capa espinosa de los tejidos, mientras que los péptidos pueden ser detectados en las capas espinosas superiores, granular y queratinizadas. Sin embargo la expresión más fuerte es en el margen gingival, cerca de donde ocurre la mayor for- 
mación de placa bacteriana y en el epitelio del surco inflamado (52).

Con relación a la expresión de este péptido en tejidos enfermos, se comprobó que la expresión de genes de hBD-l y 2 es menos frecuentemente detectada en tejidos con gingivitis que en encía sana por medios de reacción de cadena en polimerasa de tiempo real (RTPCR). El ARNm de hBD-1 y 2 fue solamente detectado en el $66 \%$ y $86 \%$, respectivamente, de biopsias de pacientes con gingivitis, mientras que el ARNm de hBD-3 se encontró en el $100 \%$ de todas las muestras de gingivitis (53); sin embargo el ARNm de B-defensinas fue también detectado en menor frecuencia en muestra de pacientes con periodontitis. En comparación con las biopsias de tejidos gingivales sanos, la expresión de ARNm de hBD-l fue vista en $60 \%$ de las muestras de periodontitis, mientras que las hBD-2 y 3 fue detectada en menos del $40 \%$ de las muestras.

Otro estudio reciente, analizó la expresión de $ß$ defensinas humanas 1 y 2 en encía de pacientes con gingivitis, periodontitis agresiva y periodontitis crónica a través de RT-PCR. Este estudio demostró, que la expresión de hBD-l en el grupo de pacientes con periodontitis crónica fue significativamente mayor que aquellos con gingivitis y periodontitis agresiva (54); sin embargo la expresión de hBD-3 es reportada en la capa basal celular en muestras de tejido sano, y en las capas celulares espinosas y basales en muestras de pacientes con enfermedad periodontal (55).

Alguna evidencia sugiere que los comensales y patógenos usan mecanismos diferentes de regulación para la inducción de hBD-2 y que su regulación puede diferir en la mucosa oral a otros tejidos. La regulación de hBD-2 por las bacterias comensales cómo F. nucleatum, es independiente de otras respuestas inmunes innatas, tales como expresión de IL-8; un quimioatrayente de neutrófilos. No obstante, los LPS de $P$. gingivalis, $F$ nucleatum y $E$. coli son pobres estimulantes de hBD-2 en células epiteliales gingivales cultivadas, sugiriendo la inclusión de vías de señalización más que activación de la señalización de los TLR-4 por los LPS (56). La evidencia sugiere que los TLR 2 y 4 no juegan un rol mayor en la inducción de hBD-2 por bacterias orales y sugieren que la inducción de hBD-2 por bacterias patogénicas pueden utilizar algo más que la vía de la señalización de LPS-TLR4 como los PARs (receptores activados por proteasas) (57).

La regulación de la expresión de hBD-3 difiere de la de hBD-2 en que la hBD-3 está presente en células epiteliales gingivales estimuladas y no estimuladas, además, no responden a P. gingivalis o a los activadores de los PARs. Las hBD-3 son ampliamente expresadas en tejidos orales inflamados y no inflamados, sugiriendo un rol importante de la hBD-3 así como de la hBD-2 en la respuesta inmune innata en la cavidad oral.

Lu et al, en 2005 (57), en un estudio para determinar los niveles de $B$ defensinas tipo 3 , en biopsias gingivales de sujetos con periodontitis crónica vs sujetos sanos, a través de técnicas de inmunohistoquímica in situ; reportan que el péptido hBD-3 se detectó en el $88 \%$ de las muestras, que se encuentra confinado al epitelio gingival. En sujetos de control el hBD-3 fue más frecuente en la capa basal al comparar con los sujetos enfermos ( $53 \%$ vs $18 \%$ respectivamente). Lo cual sugiere que la expresión apropiada de hBD-3 puede contribuir al mantenimiento de la homeostasis periodontal, posiblemente a través de su efecto antimicrobiano y promoción de la respuesta inmune adaptativa.

También es ampliamente conocido el papel de las proteínas de choque térmico-60 (hsp60) que se definen como moléculas antigénicas expresadas durante los procesos periodontales crónicos; pertenecen a la familia de proteínas que se consideran durante la evolución. A pesar de la alta homología de las defensinas en las células eucarióticas y procarióticas, las hsp60 son fuertemente inmunogénicas, y se especula que inician las enfermedades inflamatorias crónicas en las cuales la respuesta autoinmune a la hsp60 puede ser central en el proceso patogénico (58).

Se evidencia, también, que las bacterias periodontopatógenas tales como $P$. gingivalis (59-61), A. actinomycetemcomitans (62), F. nucleatum, $P$. intermedia, $B$. forsythus (63) y C. rectus (64) producen homólogos al GroEL (chaperonina - antígeno exógeno) de E. coli.

Este tipo de proteínas, juegan papeles importantes en la relación causal entre las infecciones microbianas y la autoinmunidad debido a la conservación de la secuencia de aminoácidos durante la evolución de la enfermedad demostrada y su fuerte inmunogenicidad. Se demuestran anticuerpos séricos para las bacterias periodontopatógenas derivados de hsp60; estos anticuerpos son frecuentemente detectados en pacientes con periodontitis (65). Aunque los mecanismos precisos por los cuales los anticuerpos antihsp60 se encuentran elevados no se comprenden perfectamente, aquellos con altos títulos de anticuerpos pueden ser sensibilizados con otras bacterias más que con periodontopatógenos. 
Existe también evidencia que sugiere que la inflamación resulta de una mayor regulación de hsp y un número de hsp60 expresadas en las células puede ser encontrada en los infiltrados celulares inflamatorios y en el tejido gingival inflamado. Como resultado de ésta mayor regulación, las células T-específicas para autohsp60 puede ser activado como una parte de la respuesta inflamatoria normal. Sin embargo, considerando la expresión de hsp60 en las lesiones inflamatorias de periodontitis y la presencia de anticuerpos antihsp60, no solamente ejerce efectos patogénicos en el sitio de la inflamación y contribuye a la progresión de destrucción periodontal a través de la fijación del sistema de complemento, así como también citotoxicidad T, dependiente de los anticuerpos.

Se reconocen también estas proteínas debido a que estimulan los monocitos para que produzcan citoquinas proinflamatorias (2) o para regular la expresión de moléculas de adhesión. Recientemente se demostró que las hsp60 humanas pueden también activar el sistema inmune innato. Sumado a lo anterior, Ueki et al (66), en 2002, determina que las hsp60 humanas pero no bacterianas (periodontopatógenos) puede inducir a la producción de FNT- $\alpha$, en los macrófagos y que esta actividad es mediada, por lo menos, en parte por los CD14 y TLR4; los cuales se conocen son receptores de LPS. Por tanto, las hsp60 de P. gingivalis y A. actinomycetemcomitans, pueden tener menor efecto en la inducción de citoquinas proinflamatorias que otras bacterias. Sin embargo el hallazgo sorprendente fue que la hsp60 humana es un potente inductor de TNF- $\alpha$ en los macrófagos. También fue posible confirmar en ese estudio que los receptores CDI4 y TLR4 son vías importantes en la mediación de la activación de macrófagos en respuesta a la hsp60 humana. El rol de las hsp60 en la patogénesis de la enfermedad periodontal no está totalmente dilucidado, sin embargo, considerando la abundante expresión de TLR4 y hsp60 por varios tipos de células en las lesiones periodontales y los efectos estimulantes en el sistema inmune, se espera un rol patológico de la hsp60.

Otros estudios también reportan que las hsp60, estimulan significativamente la producción de IFN- y en pacientes con periodontitis, sugiriendo entonces, que la respuesta proliferativa a las hsp60 humana son probablemente selectivas en el estímulo de células T específicas con un perfil tipo-l de citoquinas. Alternativamente es concebible que las hsp60-específicas de células T pueden estar incluidas en los procesos de destrucción tisular a través de la producción de citoquinas proinflamatorias por los macrófagos y otros mediadores como la $\mathrm{PGE}_{2}$. La razón más probable para la alta reactividad frente a las hsp60 en los pacientes con periodontitis sigue sin esclarecer. Se requieren estudios posteriores para dilucidar el rol de las hsp60específica para células $\mathrm{T}$ en los procesos inflamatorios crónicos tales como periodontitis.

Tal y cómo fundamenta ampliamente este documento, el papel de las macromoléculas proteínas en el desarrollo de la enfermedad periodontal se resume entonces en mediadores de expresión de otras moléculas, cambios en la morfología celular, activación de células para secreción de sustancias y de esta manera establecer o exacerbar el daño tisular. Toda esta evidencia, sugiere que se debe analizar la patología periodontal ampliando su concepto a la inclusión de las proteínas como reguladores de los procesos fisiológicos y metabólicos, de allí, la fundamentación para establecer en la literatura científica, el papel de las proteínas expresadas en la periodontitis, como facilitadores de vías de exploración de este tipo de enfermedades desde su naturaleza, la respuesta inmune.

\section{BIBLIOGRAFÍA}

1. Pihlstrom BL, Michalowicz BS, Johnson NW. Periodontal diseases. Lancet. 2005 Nov 19;366(9499):1809-20.

2. Gemmel E, Marshall RI, Seymour GJ. Cytokines and prostaglandins in immune homeostasis and tissue destruction in periodontal disease. Periodontol 2000. 1997 Jun; 14:112-43.

3. Masada MP, Persson R, Kenney JS, Lee SW, Page RC, Allison AC. Measurement of interleukin-l alpha and 1 beta in gingival crevicular fluid: implications for the pathogenesis of periodontal disease. J Periodontal Res. 1990 May;25(3):156-63.

4. Stashenko P, Fujiyoshi P, Obernesser MS, Prostak L, Haffajee AD, Sockransky SS. Levels of interleukin 1 beta in tissue from sites of active periodontal disease. J Clin Periodontol. 1991 Aug;18(7):548-54.

5. Bufut U, Develioglu H, Taner IL, Berker E. Interleukin 1 beta levels in gingival crevicular fluid in type 2 diabetes mellitus and adult periodontitis. J Oral Sci. 2001 Sep;43(3):171-7.

6. Medzhitov R. Recognition of microorganisms and activation of the immune response. Nature. 2007 Oct 18;449(7164):819-26. 
7. Valente AJ, Graves DT, Vialle-Valentin CE, Delgado R, Schwartz CJ. Purification of a monocyte chemotactic factor secreted by nonhuman primate vascular cells in culture. Biochemistry. 1988 May 31;27(11):4162-8.

8. Jiang Y, Beller D, Frendl G, Graves D. Monocyte chemoattractant protein-l regulates adhesion molecule expression and cytokine production in human monocytes. J Immunol. 1992 Apr 15; 148(8):2423-8.

9. Rollins BJ, Sunday ME. Suppression of tumor formation in vivo by expression of the JE gene in malignant cells. Mol Cell Biol. 1991 Jun;11(6):3125-31.

10. Yu XH, Antoniades H, Graves D. Expression of monocyte chemoattractant protein-1 in human inflamed gingival tissues. Infect Immun. 1993 Nov;61(11):4622-28.

11. Ozaki K, Hanazawa S, Takeshita A, Chen Y, Watanabe A, Nishida $\mathrm{K}$, et al. Interleukin-1 beta and tumor necrosis factor-alpha stimulate synergistically the expression of monocyte chemoattractant protein-l in fibroblastic cells derived from human periodontal ligament. Oral Microbiol Immunol. 1996 Apr;11(2):109-14.

12. Tonetti MS, Imboden MA, Gerber L, Lang NP, Laissue J, Mueller C. Localized expression of mRNA for phagocyte-specific chemotactic cytokines in human periodontal infections. Infect Immun. 1994 Sep;62(9):4005-14.

13. Pradeep AR, Daisy H, Hadge P. Gingival crevicular fluid levels of monocyte chemoattractant protein-1 in periodontal health and disease. Arch Oral Biol. 2009 May;54(5):503-9. Epub 2009 Mar 16.

14. Pepys MB, Hirschfield GM. C reactive protein: a critical update. J Clin Invest. 2003 Jun; 11 (12):1805-12.

15. Sanders AE, Slade GD, Fitzsimmons TR, Bartold PM. Physical activity, inflammatory biomarkers in gingival crevicular fluid and periodontitis. J Clin Periodontol. 2009 May;36(5):388-95.

16. Linden GJ, McClean K, Young I, Evans A, Kee F. Persistently raised C-reactive protein levels are associated with advanced periodontal disease. J Clin Periodontol. 2008 Sep;35(9):741-7. Epub 2008 Jul 21.

17. Fagerhol MK, Andersson KB, Naess- Andresen CF, Brandtzaeg P, Dale I. Calprotectin (The Ll leukocyte protein). In: Stimulus response coupling: The role of intracellular calcium-binding proteins, eds. Smith, V. L.
\& Dedman, J. R., 1990 pp. 187-210. Boca Raton Ann Arbor Boston: CRC Press.

18. Dale I, Fagerhol MK, Naesgaard I. Purification and partial characterization of a highly immunogenic human leukocyte protein, the Ll antigen. Eur J Biochem. 1983 Jul 15;134(1):1-6.

19. Brandtzaeg P, Dale I, Fagerhol MK. Distribution of a formalin-resistant myelomonocytic antigen (Ll) in human tissues. (II). Normal and aberrant occurrence in various epithelia. Am J Clin Pathol. 1987 Jun;87(6):700-7.

20. Golden BE, Clohessy PA, Russell G, Fagerhol MK. Calprotectin as a marker of inflammation in cystic fibrosis. Arch Dis Child. 1996 Feb;74(2):136-9.

21. Kido J, Nishikawa S, Ishida H, Yamashita K, Kitamura S, Kohri K, Nagata T. Identification of calprotectin, a calcium binding leukocyte protein, in human dental calculus matrix. J Periodontal Res. 1997 May;32(4):355-61.

22. Kido J, Nakamura T, Kido R, Ohishi K, Yamauchi N, Kataoka M, Nagata T. Calprotectin, a leukocyte protein related to inflammation, in gingival crevicular fluid. J Periodontal Res. 1998 Oct;33(7):434-7.

23. Schlegel Gómez R, Langer P, Pelka M, von den Driesch $\mathrm{P}$, Johannessen AC, Simon M Jr. Variational expression of functionally different macrophage markers (27E10, $25 \mathrm{~F} 9, \mathrm{RM} 3 / 1$ ) in normal gingival and inflammatory periodontal disease. J Clin Periodontol. 1995 May;22(5): 341-6.

24. Miyasaki KT. The neutrophil: mechanisms of controlling periodontal bacteria. J Periodontol. 1991 Dec;62(12): 761-74.

25. Nisapakultorn K, Ross KF, Herzberg MC. Calprotectin expression in vitro by oral epithelial cells confers resistance to infection by Porphyromonas gingivalis. Infect Immun. 2001 Jul;69(7):4242-7.

26. Yui S, Yang D, Mikami M, Yamazaki M. Purification and characterization of the cytotoxic factor in rat peritoneal exudate cells: its identification as the calcium binding protein complex, calprotectin. J Leukoc Biol. 1995 Sep;58(3):307-16.

27. Kido J, Kido R, Kataoka M, Suryono, Fagerhol MK, Nigata T. Lipopolysaccharide of $\mathrm{P}$ gingivalis induces calprotectin secretion from human neutrophils. J Dent Res 2001;80(Special Issue):535. 
28. Watanabe A, Takeshita A, Kitano S, Hanazawa S. CD14mediated signal pathway of Porphyromonas gingivalis lipopolysaccharide in human gingival fibroblasts. Infect Immun. 1996 Nov;64(11):4488-94.

29. Chow JC, Young DW, Golenbock DT, Christ WJ, Gusovsky F. Toll-like receptor-4 mediates lipopolysaccharideinduced signal transduction. J Biol Chem. 1999 Apr 16; 274(16):10689-92.

30. Tabeta K, Yamazaki K, Akashi S et al. Toll-like receptors confer responsiveness to lipopolysaccharide from Porphyromonas gingivalis in human gingival fibroblasts. Infect Immun. 2000 Jun;68(6):3731-5.

31. Wang P, Azuma Y, Shinohara M, Ohura K. Toll-like receptor 4-mediated signal pathway induced by Porphyromonas gingivalis lipopolysaccharide in human gingival fibroblasts. Biochem Biophys Res Commun. 2000 Jul 14;273(3):1161-7.

32. Hiroi M, Shimojima T, Kashimata $\mathrm{M}$ et al. Inhibition by Porphyromonas gingivalis LPS of apoptosis induction in human peripheral blood polymorphonuclear leukocytes. Anticancer Res. 1998 Sep-Oct;18(5A): 3475-9.

33. Kido J, Nakamura T, Kido R, Ohishi K, Yamauchi N, Kataoka M, Nagata T. Calprotectin in gingival crevicular fluid correlates with clinical and biochemical markers of periodontal disease. J Clin Periodontol. 1999 Oct;26(10):653-7.

34. Colognato H, Yurchenco PD. Form and function: the laminin family of heterotrimers. Dev Dyn. 2000 Jun;2 18 (2):213-34.

35. O'Toole EA. Extracellular matrix and keratinocyte migration. Clin Exp Dermatol. 2001 Sep;26(6):52530.

36. Pöllänen MT, Salonen JI. Uitto VJ. Structure and function of the tooth-epithelial interface in health and disease. Periodontol 2000. 2003;31:12-31.

37. Gürses N, Thorup AK, Reibel J, Carter GW, Holmstrup P. Expression of VLA-integrins and their related basement membrane ligands in gingiva from patients of various periodontitis categories. J Clin Periodontol. 1999 Apr;26 (4):217-24.

38. Tryggvason K. The laminin family. Curr Opini Cell Biol. 1993 Oct;5(5):877-82.
39. Gagnoux-Palacios L, Allegra M, Spirito F, Pommeret O, Romero C, Ortonne JP, Meneguzzi G. The short arm of the laminin gamma2 chain plays a pivotal role in the incorporation of laminin 5 into the extracellular matrix and in cell adhesion. J Cell Biol. 2001 May 14;153(4):835-50.

40. Pirilä E, Maisi P, Salo T, Koivunen E, Sorsa T. In vivo localization of gelatinases (MMP-2 and -9) by in situ zymography with a selective gelatinase. Biochem Biophys Res Commun. 2001 Sep 28;287(3):766-74.

41. Kivelä-Rajamäki MJ, Teronen OP, Maisi P, Husa V, Tervahartiala TI, Pirilä EM, Salo TA, Mellanen L, Sorsa TA. Laminin-5 gamma2-chain and collagenase-2 (MMP8) in human peri-implant sulcular fluid. Clin Oral Implants Res. 2003 Apr; 14(2):158-65.

42. Figueredo CMS, Gustafsson A: Increased amounts of laminin in GCF from untreated patients with periodontitis J Clin Periodontol. 2000 May;27(5):313-8.

43. Ouhara K, Komatsuzawa H, Yamada S, Shiba H, Fujiwara T, Ohara M, et al. Susceptibilities of periodontopathogenic and cariogenic bacteria to antibacterial peptides, $\{$ beta $\}$ defensins and LL37, produced by human epithelial cells. J Antimicrob Chemother. 2005 Jun;55(6):888-96. Epub 2005 May 10.

44. Harder J, Bartels J, Christophers E, Schroder JM. Isolation and characterization of human beta -defensin-3, a novel human inducible peptide antibiotic. J Biol Chem. 2001 Feb 23;276(8):5707-13. Epub 2000 Nov 20.

45. van Wetering S, Sterk PJ, Rabe KF, Hiemstra PS. Defensins: key players or bystanders in infection, injury, and repair in the lung? J Allergy Clin Immunol. 1999 Dec;104(6):1131-8.

46. Lehrer RI, Lichtenstein AK, Ganz T. Defensins: antimicrobial and cytotoxic peptides of mammalian cells. Annu Rev Immunol. 1993;1 1:105-28.

47. Mizukawa N, Sugiyama K, Ueno T, Mishima K, Takagi S, Sugahara T. Levels of human defensin-1, an antimicrobial peptide, in saliva of patients with oral inflammation. Oral Surg Oral Med Oral Pathol Oral Radiol Endod. 1999 May; 87(5):539-43.

48. Dale BA. Periodontal epithelium: a newly recognized role in health and disease. Periodontol 2000. 2002;30:70-8.

49. Valore EV, Park CH, Quayle AJ, Wiles KR, McCray PB Jr, Ganz T. Human beta-defensin-1: an antimicrobial 
peptide of urogenital tissues. J Clin Invest. 1998 Apr 15; 101(8):1633-42.

50. Diamond DL, Kimball JR, Krisanaprakornkit S, Ganz T, Dale BA. Detection of beta-defensins secreted by human oral epithelial cells. J Immunol Methods. 2001 Oct $1 ; 256(1-2): 65-76$.

51. Mizukawa N, Sawaki K, Yamachika E, Fukunaga J, Ueno T, Takagi S, et al. Presence of human beta-defensin-2 in oral squamous cell carcinoma. Anticancer Res. 2000 May-Jun;20(3B):2005-7.

52. Krisanaprakornkit S, Kimball JR, Weinberg A, Darveau $\mathrm{RP}$, Bainbridge BW, Dale BA. Inducible expression of human beta-defensin 2 by Fusobacterium nucleatum in oral epithelial cells: multiple signaling pathways and role of commensal bacteria in innate immunity and the epithelial barrier. Infect Immun. 2000 May;68(5): 2907-15.

53. Chung WO, Dale BA. Innate immune response of oral and foreskin keratinocytes: utilization of different signaling pathways by various bacterial species. Infect Immun. 2004 Jan;72(1):352-8.

54. Dale BA, Kimball JR, Krisanaprakornkit S, Roberts F, Robinovitch M, O'Neal R, Valore EV, Ganz T, Anderson GM, Weinberg A. Localized antimicrobial peptide expression in human gingiva. J Periodontal Res. 2001 Oct;36(5):285-94.

55. Dunsche A, AcilY, Dommisch H, Siebert R, Schroder JM, Jepsen $\mathrm{S}$. The novel human beta-defensin-3 is widely expressed in oral tissues. Eur J Oral Sci. 2002 Apr;110(2):121-4.

56. Vardar-Sengul S, Demirci T, Sen BH, Erkizan V, Kurulgan E, Baylas H. Human beta defensin-1 and -2 expression in gingiva of patients with specific periodontal diseases. J Periodontal Res. 2007 Oct;42(5):429-37.

57. Lu Q, Samaranayake LP, Darveau RP, Jin L. Expression of human beta-defensin-3 in gingival epithelia. J Periodontal Res. 2005 Dec;40(6):474-81.

58. ChungWO, Hansen SR, Rao D, Dale BA. Protease-activated receptor signaling increases epithelial antimicrobial peptide expression. J Immunol. 2004 Oct 15;173(8): 5165-70.
59. Kiessling R, Gronberg A, Ivanyi J, Soderstrom K, Ferm $\mathrm{M}$, Kleinau S, Nilsson E, Klareskog L. Role of hsp60 during autoimmune and bacterial inflammation. Immunol Rev. 1991 Jun;121:91-111.

60. Hotokezaka H, Hayashida H, Ohara N, Nomaguchi H, Kobayashi K, Yamada T. Cloning and sequencing of the groEL homologue from Porphyromonas gingivalis. Biochim Biophys. Acta. 1994 Sep 13;1219(1):175-8.

61. Maeda H, Miyamoto M, Hongyo H, Nagai A, Kurihara H, Murayama Y. Heat shock protein 60(GroEL) from Porphyromonas gingivalis: molecular cloning and sequence analysis of its gene and purification of the recombinant protein. FEMS Microbiol Lett. 1994 Jun 1; $119(1-2): 129-35$.

62. NakanoY, InaiY,Yamashita Y, Nagaoka S, Kasuzaki-Nagira T, Nishihara T, Okahashi N, Koga T. Molecular and immunological characterization of a $64-\mathrm{kDa}$ protein of Actinobacillus actinomycetemcomitans. Oral Microbiol Immunol. 1995 Jun;10(3):151-9.

63. Vayssier C, Mayrand D, Grenier D. Detection of stress proteins in Porphyromonas gingivalis and other oral bacteria by Western immunoblotting analysis. FEMS Microbiol Lett. 1994 Sep 1;121(3):303-7.

64. Hinode D, Yoshioka M, Tanabe S, Miki O, Masuda K, Nakamura R. The GroEL-like protein from Campylobacter rectus: immunological characterization and interleukin- 6 and -8 induction in human gingival fibroblast. FEMS Microbiol Lett. 1998 Oct 1;167(1):1-6.

65. Ferber I, Schonrich G, Schenke J, Mellor AL, Hammerling GJ, Arnold B. Levels of peripheral T cell tolerance induced by different doses of tolerogen. Science. 1994 Feb 4;263(5147):674-6.

66. Ueki K, Tabeta K, Yoshie H, Yamazaki K. Self-heat shock protein induces tumor necrosis factor- $\alpha$ in monocytederived macrophage: possible role in chronic inflammatory periodontal disease. Clin Exp Immunol. 2002 Jan;127(1):72-7.

\section{CORRESPONDENCIA}

Antonio José Díaz Caballero antoniodiazc@yahoo.com 